\title{
Renuncia de regidurías: dos lecturas constitucionales
}

\section{Luis Diego Brenes Villalobos*}

https://doi.org/10.35242/RDE $2022 \quad 22 \quad 33 \quad 3$

Nota del Consejo Editorial

Recepción: 11 de octubre de 2021.

Revisión, corrección y aprobación: 12 de noviembre de 2021.

Resumen: El artículo 171 de la Constitución Política costarricense señala en su párrafo primero que los regidores municipales: "serán elegidos por cuatro años y desempeñarán sus cargos obligatoriamente". Esta disposición ha propiciado dos lecturas en el seno del Tribunal Supremo de Elecciones (en adelante TSE o el Tribunal) que discrepan respecto del alcance de la obligatoriedad del cargo y la excepcionalidad para su renuncia. El presente ensayo repasa esas tesis con particular interés en la que admite la renuncia sin necesidad de excepcionalidades, según se defendiese en la sentencia del TSE n. ${ }^{\circ} 1626-\mathrm{M}-2017$ de $1 .^{\circ}$ de marzo del 2017.

Palabras clave: Regidores municipales / Renuncia / Interpretación constitucional / Irrenunciabilidad de cargo / Puestos de elección popular / Pragmatismo judicial.

Abstract: The article 171 of the Political Constitution of the Republic of Costa Rica indicates in its first paragraph that municipal council members "shall be elected for a term of four years and their duties shall be mandatory". This provision has led to two constitutional understandings within the Supreme Electoral Tribunal (knows as TSE by its acronym in Spanish or "el Tribunal") that disagree regarding the scope of the obligation of the position and the exceptionality for its resignation. This essay reviews these theses, with particular interest in the one that admits the resignation without exceptions, as defended in the TSE resolution n. ${ }^{\circ}$ 1626-M-2017 of March 1, 2017.

Key Words: Municipal council members / Constitutional interpretation / Irrevocability of office / Popular election offices / Judicial pragmatism.

\footnotetext{
* Costarricense, abogado y politólogo, dbrenes@tse.go.cr. Doctor en Ciencia Política y Diploma de Especialización en Derecho Constitucional por la Universidad de Salamanca, España. Máster en Derecho Constitucional por la Universidad Estatal a Distancia de Costa Rica (UNED) y licenciado en Derecho por la Universidad de Costa Rica (UCR). Profesor asociado de la Facultad de Derecho en la UCR. Funcionario del Tribunal Supremo de Elecciones desde el año 2003, actualmente se desempeña como magistrado suplente. Principales líneas de investigación: elecciones, sistemas electorales, judicial politics, justicia electoral y constitucional.

El autor agradece los comentarios y colaboraciones de los funcionarios electorales Ricardo Bueno, Andrei Cambronero y Alejandro Robles. Al primero en la revisión de antecedentes legislativos, al segundo por profundas revisiones jurisprudenciales $\mathrm{y}$ al tercero por observaciones globales formuladas al paper. El enfoque e interpretación, con sus virtudes o no, son, sin embargo, de absoluta responsabilidad del autor. Agradecimiento por igual a la revisión efectuada por el par ciego de la Revista de Derecho Electoral.
} 


\section{DERECHO ELECTORAL}

\section{INTRODUCCIÓN Y ANTECEDENTES}

El tema de la aceptación o no de las renuncias presentadas por regidores y regidoras, en lo que refiere a la integración titular de magistrados propietarios del TSE, ha propiciado criterios disidentes, así como cambios de tesis a lo largo del tiempo. En un repaso a la jurisprudencia electoral desde el año 1999, tomando como año de referencia el inicio del nombramiento del magistrado Luis Antonio Sobrado González, quien a la fecha de la redacción de este artículo fungía como el más antiguo de los magistrados propietarios en ejercicio del cargo, y quien presidía el TSE desde el año 2007, varias son las posturas y razonamientos que se evidencian, incluyendo cambios de criterio entre sus integrantes que llevaron a destacadas tesis disidentes. Por ejemplo, la integración de magistrados propietarios permanentes para el año 1999, en que el TSE estaba conformado por los magistrados Óscar Fonseca Montoya, quien presidía, y los magistrados Anabelle León Feoli y Luis Antonio Sobrado González, evidencia al menos dos resoluciones (sentencias n. ${ }^{\circ}$ 886-1999 y n. ${ }^{\circ}$ 1858-1999), donde el pleno del Tribunal, por unanimidad, dispuso la cancelación de credenciales de los regidores que conocía sin advertir particularidad o excepción alguna demostrada para aceptar tal renuncia.

Las consideraciones del pleno se centraban en una lectura estricta al Código Municipal que señala como causal de pérdida de credencial de regidor "La renuncia voluntaria escrita y conocida por el Concejo" (inciso b, artículo 24). Al tenerse por demostrado que el Concejo Municipal respectivo había conocido de la renuncia, el TSE procedía a cancelar la credencial y designaba al sustituto correspondiente, dada la vacante propiciada y conforme a las reglas del artículo 25, inciso c), del Código Municipal.

Esta tesis del pleno, sin embargo, variaría para el año 2000, momento en que el magistrado Sobrado González se separa de los antecedes referidos y suscribía, mediante voto salvado, una nueva lectura, ahora de orden constitucional, que desde entonces defiende la irrenunciabilidad del cargo, aunque la permite bajo motivos excepcionales.

\section{LA TESIS DE LA IRRENUNCIABILIDAD DEL CARGO PARA LAS REGIDURÍAS}

En detalle del criterio disidente del magistrado Sobrado González, desde la resolución del TSE n. ${ }^{\circ} 696-E-2000$ se ha sostenido que deben acreditarse, por las vías probatorias idóneas, motivos excepcionales que razonablemente eximan el deber constitucional del ejercicio del cargo de 


\section{DERECHO ELECTORAL}

regidor. Según defiende ese criterio jurídico, en cita del voto salvado a esa primera sentencia:

Una de las características de la relación de servicio que vincula a los funcionarios con la Administración a la que sirven es su carácter voluntario; razón por la cual los cargos públicos son renunciables, debiéndose considerar que una renuncia de tal tipo constituye un acto unilateral, de suerte tal que no requiere aceptación alguna para que surta efecto (así lo precisaba la Procuraduría General de la República en su dictamen n. ${ }^{\circ}$ C-09298 del 19 de mayo de 1998).

La anterior regla queda excepcionada en relación con los regidores municipales, puesto que la Constitución Política estipula expresamente que éstos"... desempeñarán sus cargos obligatoriamente ..." (art. 171). Por su parte, el inciso c) del artículo 24 del Código Municipal establece, como causa de pérdida de la credencial de regidor, "La renuncia voluntaria escrita y conocida por el Concejo"; constituyendo, el anterior, uno de los supuestos en que le corresponde al Tribunal Supremo de Elecciones decretar la cancelación de tal credencial, en la inteligencia del inciso b) del artículo 25 de ese mismo Código. Dichas disposiciones deben ser interpretadas "conforme a la Constitución".

El principio de interpretación del bloque de legalidad "conforme a la Constitución", que ha sido receptado por la jurisprudencia constitucional, constituye el corolario de la eficacia directa del clausulado constitucional, como bien lo entiende la doctrina constitucionalista:

"La supremacía de la Constitución sobre todas las normas y su carácter central en la construcción y en la validez del ordenamiento en su conjunto, obligan a interpretar éste en cualquier momento de su aplicación -por operadores públicos o por operadores privados, por Tribunales o por órganos legislativos o administrativos- en el sentido que resulta de los principios y reglas constitucionales, tanto los generales como los específicos referentes a la materia de que se trate" (Eduardo García de Enterría, "La constitución como norma y el Tribunal Constitucional", Madrid, Civitas, 1988, pág. 95). 


\section{DERECHO EIECTORAL}

Por ello y en virtud del principio de unidad del ordenamiento, así como de la necesidad de rehuir del vacío que produce la invalidación normativa, frente a varias interpretaciones posibles de un precepto, ha de preferirse aquélla que salve de un potencial roce constitucional (véase en el mismo sentido Ignacio de Otto, Derecho Constitucional, sistema de fuentes, Barcelona, Ariel, 1988 , p. 80).

Igual criterio debe presidir la actividad de integración del ordenamiento para colmar sus insuficiencias. Con ello, las normas constitucionales y los principios que recogen adquieren un rol dominante en la concreción de los sentidos normativos; a lo cual va aparejada una implícita prohibición para el intérprete de recurrir a criterios hermenéuticos que conduzcan a resultados contradictorios con dichas normas y principios.

La anterior exigencia interpretativa obliga a entender que los citados numerales del Código Municipal únicamente autorizan a cancelar las credenciales del regidor que renuncia a su cargo, cuando tal renuncia se base en motivos excepcionales que razonablemente eximan al interesado del cumplimiento de su deber constitucional, previamente valorados por el respectivo Concejo Municipal. Sólo de esa manera es posible conciliar la obligatoriedad del cargo, impuesta constitucionalmente, con el principio de que nadie está obligado a lo imposible. (TSE, 2000, sentencia $n .^{\circ} 696-E-2000$, voto salvado).

A este precedente, y dadas nuevas argumentaciones en favor de la renunciabilidad del cargo de regidor formuladas en el año 2017, se adicionarían las siguientes consideraciones, segunda réplica, compartidas tanto por el magistrado Sobrado González como por la magistrada Zetty María Bou Valverde:

La decisión del constituyente originario en torno a la obligatoriedad del ejercicio de la regiduría fue tácitamente ratificada por el constituyente derivado: al momento de repensar el artículo 171 constitucional y reformarlo parcialmente en 1958 y 1961, mantuvo incólume ese rasgo de obligatoriedad, pudiendo haberlo modificado. En su lugar, suprimió únicamente su gratuidad, no siendo a nuestro juicio incompatible ni tampoco 


\section{DERECHO ELECTORAL}

contradictoria la referida obligatoriedad con el nuevo carácter remunerado del ejercicio de tal función pública. Así las cosas, estamos de frente a una norma constitucional vigente (que debe ser aplicada con mansedumbre por el operador jurídico, con independencia de su juicio personal sobre la conveniencia de la misma), claramente formulada (que por ello no puede ser desconocida por el juez -sea el ordinario o el electoral- alegando estar interpretándola) y que no roza el principio general de libertad (ni mucho menos el derecho de asociación, que no se aprecia cómo pueda estar involucrado en la situación que se analiza).

Sobre esta última afirmación, cabe recordar que la ciudadanía no sólo está conformada por un conjunto de derechos políticos, sino también por deberes de esa misma naturaleza. Por regla del constituyente, uno de estos últimos es justamente el deber de desempeñar el cargo de regidor, que se asumió a partir de la libérrima decisión de postularse, mientras no haya motivos justificados y sobrevinientes que desliguen al ciudadano de ese compromiso cívico que se contrajo ante los electores; cargo que, en todo caso, no supone una relación de empleo público y cuyo ejercicio resulta compatible con cualquier otra actividad laboral, profesional o empresarial que tenga o desee asumir el regidor. En ese tanto, no es una carga irrazonable o excesiva ni tampoco impide la realización del destino personal que cualquier persona pueda haberse fijado en un marco de libertad. Un ejemplo similar, aunque en este caso de origen legal, lo es el cargo de integrante de las juntas electorales, que el Código Electoral califica como "honorífico y obligatorio" (art. 30 y 33); al hacerlo, refuerza una visión republicana de la ciudadanía y realza la existencia de responsabilidades que atan al individuo con la polis. (TSE, 2017, sentencia n. ${ }^{\circ}$ 1626-M-2017, voto salvado).

\section{POSTURA INICIAL DEL TSE EN FAVOR DE LA RENUNCIABILIDAD DEL CARGO DE REGIDURÍAS}

La tesis de mayoría, ante la primera de las réplicas del voto disidente del magistrado Sobrado González, no se limitó a una lectura, como el pasado, estrictamente legal. De esta suerte, existe una ponderación constitucional, que se entiende complementada con la legislación ordinaria, tanto la 


\section{DERECHO EIECTORAL}

municipal como la propia de la jurisdicción constitucional. En cita expresa, los magistrados Fonseca Montoya y León Feoli señalaban:

La mayoría de los integrantes de este Tribunal, es del criterio de que la renuncia formulada por un regidor, en los términos establecidos en el inciso c) del artículo 24 del Código Municipal, constituye una causal para la cancelación de la credencial que en ese carácter ostenta.

Sin ignorar que la Constitución Política establece en el artículo 171 que el cargo es irrenunciable, es lo cierto que el legislador, en la disposición legal ya citada, la incorporó al ordenamiento jurídico, tornando su aplicación en obligatoria, de manera que la incompatibilidad que se pudiera presentar entre ambas normas, solo puede ser dilucidada en la jurisdicción constitucional, al amparo del control concentrado del derecho de la Constitución que en esa sede se ejerce.

Tómese en cuenta de que de no aceptarse la posibilidad de renuncia pura y simple, se atentaría contra un derecho fundamental: la libertad, previsto no solo en la Constitución Política, sino también en Tratados y Convenios Internacionales, siendo una de sus manifestaciones, el poder optar por mantenerse $o$ no en un determinado cargo. Por otra parte, en caso de no accederse a la posibilidad de una renuncia voluntaria, se induciría al regidor a incurrir en una causal sancionatoria, como podría ser el abandono de sesiones, con evidente lesión a los intereses de la corporación [voto de la mayoría]. (TSE, 2000, sentencia n. $\left.{ }^{\circ} 696-\mathrm{E}-2000\right)$.

Con posterioridad, en una nueva integración de magistrados propietarios del Tribunal, desde el año 2007 y hasta el 2021, los magistrados Eugenia María Zamora Chavarría y Max Alberto Esquivel Faerron, siguiendo el criterio inicialmente expuesto por la mayoría del TSE del año 2000, han sostenido que la obligatoriedad en el ejercicio del cargo que el artículo 171 de la Constitución Política dispone para con los regidores municipales debe entenderse referida al:

debido cumplimiento de las responsabilidades propias del cargo mientras se ostente la investidura, pero no a la imposibilidad de renunciar a él cuando circunstancias personales o de otro orden así lo 


\section{DERECHO ELECTORAL}

indiquen. La renuncia a cualquier cargo público, incluyendo los de elección popular, es inherente a la libertad como valor constitucional de que gozan todas las personas, pues constituye un derecho fundamental reconocido en el artículo 20 de la Constitución Política. (TSE, 2017, sentencia n. ${ }^{\circ}$ 1626-M-2017).

Según ese criterio de mayoría y en cita expresa:

De no aceptarse la posibilidad de la renuncia pura y simple se atentaría contra un derecho fundamental: la libertad, previsto no solo en la Constitución Política sino también en los instrumentos jurídicos internacionales de derechos humanos de los que es parte el Estado Costarricense, siendo una de sus manifestaciones el poder optar por mantenerse o no en determinado cargo. Igualmente, en caso de no accederse a la posibilidad de una renuncia voluntaria, se induciría al regidor a incurrir en una causal sancionatoria, como podría ser el abandono de sesiones, con evidente lesión a los intereses de la Corporación Municipal. (TSE, 2017, sentencia n. ${ }^{\circ}$ 1626-M-2017).

La tesis de mayoría expuesta desde el 2007 reitera el sentido práctico en la lectura de la normativa constitucional, frente a disposiciones legales, pero también, en invocación del derecho internacional de los derechos humanos.

\section{EN DEFENSA ADICIONAL A LA RENUNCIABILIDAD DE LAS REGIDURÍAS}

En la sentencia del TSE n. ${ }^{\circ}$ 1626-M-2017, varias veces referida en este repaso, el magistrado Brenes Villalobos, autor por igual de estas líneas, defiende la tesis que acepta la dimisión de las regidurías, sin que medien motivos excepcionales para ello; sin embargo, expresamente se han señalado tres razones adicionales para sustentar esa decisión.

\subsection{BINOMIO ENTRE OBLIGATORIEDAD Y GRATUIDAD}

En la historia constitucional costarricense, la regla de la obligatoriedad para el ejercicio del cargo de una regiduría municipal únicamente aparece, a texto expreso constitucional, en la breve Constitución Política de $1917^{1}$ y

${ }^{1}$ Constitución Política de Costa Rica del año 1917, artículo 118: 


\section{DERECHO EIECTORAL}

en la actual Constitución promulgada en 1949. En ambas constituciones, y hasta 1958 en la segunda, esa obligatoriedad se entendió ligada a la gratuidad en el ejercicio del cargo ${ }^{2}$. Con anterioridad al Código Municipal de 1970, a texto expreso en la ley, esa doble atribución para los ediles se confirmaba en las respectivas ordenanzas municipales desde 1867.

Las constituciones del siglo XIX no mencionaban expresamente ni la obligatoriedad ni la gratuidad; de hecho, únicamente la Constitución de $1844^{3}$ reitera la fórmula de la Constitución gaditana de 1812 que señalaba para el concejil la necesidad de causa legal para poder excusarse ${ }^{4}$. El repaso histórico muestra, entonces, diferentes planteamientos constitucionales, principalmente omisiones. No obstante, al menos desde 1867, refleja una larga tradición legal con una lógica clara: al no existir remuneración, no había otra forma de vincular al funcionario a su cargo y evitar la consecuente desintegración del órgano.

La revisión de los debates de la Asamblea Nacional Constituyente de 1949 (Acta n.0 99) evidencia la preocupación y consideración del Constituyente al respecto; por ejemplo, el diputado Álvaro Chacón Jinesta, junto a otros constituyentes, mocionó para que se eliminasen ambos atributos bajo el razonamiento de que uno de los motivos principales para la desintegración de las municipalidades era la falta de remuneración. Aunque la propuesta sería rechazada y la Constitución de 1949 mantendría ambas cualidades de obligatorio y gratuito, nueve años después, mediante Ley n. ${ }^{2} 2214$ del 6 de junio de 1958, el tema se retomaría y el artículo 171 constitucional sería

Los Regidores propietarios y suplentes duran seis años y se renovarán por mitades cada tres años. Si el número fuere impar, se renovará primero la mitad del número par que resulte agregando una unidad al total. La suerte decidirá cuál o cuáles Regidores han de dejar su puesto en el primer trienio.

El Síndico dura tres años y se elegirá, al mismo tiempo que los Regidores, por los ciudadanos del distrito. Los cargos de Regidor y Síndico son obligatorios y gratuitos. La ley señalará los requisitos que han de tener tales funcionarios y los motivos por que puedan excusarse de servirlos.

El Intendente y el Vice-Intendente durarán en sus puestos tres años y son reelegibles. El cargo de Intendente es remunerado. Su dotación se fijará por la Municipalidad para el período siguiente y no podrá ser aumentada ni disminuida para el trienio en curso.

Los funcionarios municipales contarán sus términos desde el primero de mayo, día en que tomarán posesión. (Obregón, 2007, p. 127).

2 Constitución Política de Costa Rica del año 1949, artículo 171 en su versión original hasta el año 1961:

Los Regidores municipales serán elegidos por cuatro años y desempeñaran [sic] sus cargos gratuita y obligatoriamente.

La ley determinará el número de regidores y la forma en que actuarán. Sin embargo, las Municipalidades de los cantones centrales de provincias estarán integradas por no menos de cinco regidores propietarios e igual número de suplentes.

Las Municipalidades se instalarán el primero de julio del año correspondiente.

3 Constitución Política del año 1844, artículo 177: "Todos los destinos municipales son carga concejil de que ninguno podrá excusarse [sic] sin causa legal" (Obregón, 2007, p. 132).

${ }_{4}$ Constitución Política de la Monarquía Española del año 1812, artículo 319: "Todos los empleos municipales referidos serán carga concejil, de que nadie podrá excusarse sin causa legal". 


\section{DERECHO ELECTORAL}

reformado para habilitar el pago de dietas a los regidores. La reforma constitucional, centrada en esa retribución, se encargó únicamente de eliminar la calidad de gratuita en el desempeño de ese cargo, dejando la mención de obligatoriedad en los términos que aún conserva la redacción del citado numeral 171 y abandonando la construcción legal de entender ambos elementos como inseparables.

La revisión del expediente legislativo de esa reforma constitucional de 1958 evidencia una discusión que no ponderó lo correspondiente a la obligatoriedad del cargo, sino solamente su remuneración, en cita expresa del dictamen de la Comisión Especial se advertía:

La gratuidad en el desempeño de los cargos de concejiles la hemos tenido en Costa Rica como una cuestión de tradición: como la manifestación más pura del espíritu público de los ciudadanos. Así ha resultado en muchos casos; pero es lo cierto que, aún bajo sistema de regímenes municipales tutelados por el Poder Ejecutivo, y en Corporaciones locales de cierta importancia, la falta de remuneración a los Regidores ha producido un cierto alejamiento de ciudadanos capaces pero que, por su posición económica, no pueden llevar al mismo tiempo su trabajo diario y corriente, y el de un cargo concejil que en muchas ocasiones, además del tiempo para reuniones, requiere estudios en comisiones especiales, inspecciones de obras o trabajos, visitas a oficinas gubernamentales y aún gastos personales para transportes o para la atención de visitantes de importancia (1958, Expediente Legislativo a reforma constitucional del artículo 171, folio 16).

La exposición de motivos de esa reforma fue clara en señalar que no era justo ni conveniente que tales cargos fuesen gratuitos, dado el volumen de operaciones de las municipalidades en aquel momento. Posteriormente, con la entrada en vigencia del Código Municipal de 1970 se receta a nivel legal la remuneración del cargo, con lo que se torna obligatorio el pago de dietas a los regidores y se configura en el elemento de sujeción y en el generador de compromiso y contraprestaciones recíprocas.

La evolución histórica y los cambios normativos e institucionales denotan que la reforma constitucional de 1958 al artículo 171 también debía suprimir del texto el carácter obligatorio para los regidores, y no solamente su gratuidad. Tal omisión obliga a una interpretación basada en esos 


\section{DERECHO EIECTORAL}

antecedentes, así como a una interpretación que en sí misma sea histórica, evolutiva y sistemática.

\subsection{ChOQUe ENTRE NORMAS CONSTItUCIONALES}

La tesis de la mayoría del Tribunal entiende que la posibilidad de renuncia de los regidores encuentra asidero en la libertad, como valor constitucional de que gozan todas las personas y en tanto constituye un derecho fundamental reconocido en el artículo 20 de la Constitución Política. En complemento y adición a esa consideración, se sostiene que derivar del artículo 171 constitucional la obligatoriedad en el ejercicio del cargo de la regiduría como sinónimo de irrenunciabilidad, conllevaría un enfrentamiento adicional con el artículo 25 de la Constitución que reconoce, como derecho fundamental, la libertad de asociación, prerrogativa ciudadana cuya vertiente negativa supone la posibilidad de dejar -unilateralmente y sin justificación alguna- un grupo $y$, entiéndase también, un puesto o cargo.

Frente a tal antinomia entre normas constitucionales, se impone un ejercicio hermenéutico que no solo lleve a la coherencia como atributo del derecho de la Constitución (interpretación sistemática), sino también a la lectura que sea mayormente proclive a la seguridad como fin del derecho. En este orden de ideas, importa indicar que el citado ordinal 171 constitucional dispone, expresamente, en su párrafo segundo que "La ley determinará el número de Regidores y la forma en que actuarán", de manera que el propio constituyente autorizó al legislador ordinario para que regulara el régimen propio de los integrantes del órgano deliberante de los gobiernos locales.

Desde esa lógica, el numeral 25 del Código Municipal vigente condiciona la cancelación de credencial de los ediles a las causales previstas en ese cuerpo normativo (y en otros instrumentos de rango legal), reenvío normativo que lleva a admitir la renuncia como motivo de supresión de la credencial, pues tal presupuesto se encuentra tasado en el inciso c) del artículo 24 del citado Código. Tal interpretación tiene, como elemento virtuoso, el de resolver la contradicción normativa a partir de elementos previstos en el propio ordenamiento jurídico, dándose certeza jurídica y limitándose la discrecionalidad y resolución casuística del juez en la determinación de supuestos en los que excepcionalmente se podría admitir 


\section{DERECHOELECTORAL}

una dimisión a fin de no hacer nugatoria la libertad genérica y de asociación antes reseñada.

\subsection{Pragmatismo judicial}

Finalmente, se coincide con la tesis de la mayoría del Tribunal en cuanto a que no permitir la posibilidad de una renuncia voluntaria induciría al regidor a incurrir en una causal sancionatoria como podría ser el abandono de sesiones, con evidente lesión a los intereses de la corporación municipal.

Para mayor ahondamiento debe tenerse presente que concebir el cargo de regidor como obligatorio conllevaría que, en la práctica, quien esté ocupando un escaño en un concejo municipal y no pueda ejercerlo deba, por ejemplo, dejar de asistir a las sesiones del gobierno local por más de dos meses consecutivos a fin de poder invocar una causal válida para la supresión de su credencial. Ese escenario provoca disfunciones en el quórum de tales órganos colegiados, y puede -en casos extremos- generar la parálisis de la dinámica del municipio $y$, también de relevancia, perjudicar la dinámica política de las diversas fracciones representadas en el seno del respectivo concejo. Con la renuncia, la posibilidad de que la autoridad electoral sustituya al funcionario dimitente se torna en inmediata, con la designación del sustituto en lapsos más breves y, por ende, se genera estabilidad en criterios, deliberaciones y votación de asuntos.

Los jueces -en especial los constitucionales- tienen como parte de sus funciones realizar aplicaciones e interpretaciones del derecho que permitan traer a valor presente los preceptos jurídicos, pues, en caso contrario, la producción normativa estaría determinada a caer en la obsolescencia. De acuerdo con lo anterior, el Tribunal Supremo de Elecciones, en su rol de juez constitucional especializado en materia electoral debe procurar que las pautas relacionadas con el fenómeno electoral sean leídas conforme a la doctrina anglosajona del "Living Constitution", a fin de permitir la evolución de las normas y su encuadre con las nuevas dinámicas sociales, siempre teniendo como límite los derechos fundamentales de la ciudadanía y la imposibilidad de sustituir al legislador en su primordial función de creador de la ley como fuente privilegiada de derecho. 


\section{DERECHO EIECTORAL}

\section{Corolario}

Independientemente de la postura de mayoría o minoría del Tribunal como un todo, cuestión que finalmente queda resuelta por las posiciones de quienes lo integren en un momento determinado, es clara la diversidad de lecturas que el numeral 171 constitucional ha tenido entre varios de sus jueces electorales. El debate y análisis sigue abierto.

En la elaboración jurisprudencial, al menos respecto de la nota separada que suscribo desde el 2017, evité la réplica de la réplica, en tanto entiendo que las argumentaciones expuestas se sostienen por sí mismas. Sin embargo, en el marco del debate académico y reflexión que la Revista de Derecho Electoral siempre ha propiciado, me permito señalar tres breves consideraciones.

La lectura propuesta no pretende ser antojadiza o un juicio personal de conveniencia; procura una interpretación que en sí misma sea histórica, evolutiva y sistemática. Busca, además, certeza jurídica y lectura integral normativa en el diálogo legal y constitucional. Aspira, por igual, a un sentido judicial pragmático. El estudio de fondo me parece que así lo resguarda.

Claramente, las nuevas posiciones discrepan, a tal punto que el juicio personal de conveniencia alegado podría replicarse como también presente en la resolución casuística del juez; lo anterior cuando, discrecionalmente, se determinan los supuestos en los que excepcionalmente sí se podría admitir una dimisión.

Asimismo, defiendo la argumentación ampliada, en cuanto a que el choque de normas constitucionales no lo es únicamente entre los artículos 20 y 171 , sino que también incluye al numeral 25, referido este último a la libertad de asociación, en el escenario de que una renuncia al cargo esté intrínsecamente ligada a la renuncia de una agrupación política determinada; es decir, en paralelo se realiza la separación de un partido político sin interés de continuar con el ejercicio mismo del cargo o, incluso, por la renuncia al partido, se renuncia al escaño municipal. Si bien es cierto podría mantenerse el ejercicio de la regiduría, aunque separado de la agrupación política, sea como trásfuga o bajo el calificativo de independiente, el supuesto en consideración, con ambas renuncias en paralelo, no puede omitir esa libertad ciudadana de asociación en su vertiente negativa. Al poder dejarse unilateralmente, y sin justificación 


\section{DERECHO ELECTORAL}

alguna a una agrupación política, concomitantemente esa separación podría conllevar la renuncia al cargo por el partido que le postuló.

Finalmente, el repaso histórico evidencia el llamado binomio entre gratuidad y obligatoriedad. Traer a colación el ejemplo del cargo de integrante de las juntas electorales, precisamente coincide y refuerza lo expuesto, ya que a los calificativos de honorífico y obligatorio, que la legislación electoral les destaca a estos integrantes, se une la ausencia de una retribución o pago al efecto.

\section{REFERENCIAS BIBLIOGRÁFICAS}

Brenes, L. D. (2012). El rol político del juez electoral. San José: Editorial IFED-TSE.

Brenes, L. D. (2015). Votar Importa. San José: Editorial IFED-TSE y Fundación Konrad Adenauer.

Brenes, L. D. (2018). Informe de labores 2018, magistrado propietario (del 4 de febrero de 2017 al 4 de agosto de 2018). Recuperado de https://www.tse.go.cr/curriculum_brenes_villalobos.htm

Brenes, L. D. (2020). Informe de labores 2020, magistrado propietario (del 2 de febrero de 2019 al 5 de mayo de 2020). Recuperado de https://www.tse.go.cr/curriculum_brenes_villalobos.htm

Brenes, L. D. (2021a). Informe de labores 2021, magistrado suplente (del 7 de diciembre de 2015 al 6 de mayo de 2021). Recuperado de https://www.tse.go.cr/curriculum_brenes_villalobos.htm

Brenes, L. D. (2021b). Debates contemporáneos en la justicia electoral y rendición de cuentas. Revista de Derecho Electoral, n. ${ }^{\circ} 32$, Tribunal Supremo de Elecciones.

Costa Rica (1949). Constitución Política de Costa Rica. Versión original de 1949. Recuperado de Sistema Costarricense de Información Jurídica (SCIJ), http://www.pgrweb.go.cr/scij/Busqueda/Normativa/Normas/nrm_texto_com pleto. aspx?param $1=$ NRTC\&nValor $1=1 \&$ nValor $2=871 \&$ nValor $3=928 \&$ strTipM $=$ TC

Costa Rica (1958) Ley $n .^{\circ} 2214$ del 6 de junio, reforma al artículo 171 de la Constitución Política de Costa Rica. San José: Asamblea Legislativa de la República de Costa Rica. Expediente Legislativo. 


\section{DERECHO EIECTORAL}

Costa Rica (2021). Constitución Política de Costa Rica. Versión vigente. Recuperado de https://www.tse.go.cr/pdf/normativa/constitucion.pdf

España (1812).Constitución Política de la Monarquía Española. Recuperado de https://www.congreso.es/constitucion/ficheros/historicas/cons_1812.pdf

Obregón, C. (editora). (2007a). Costa Rica, la constitución de la provincia, los textos constitucionales y los proyectos 1812-1823. En Las Constituciones de Costa Rica, Volumen I. San José: Editorial UCR.

Obregón, C. (editora). (2007b). Costa Rica, las constituciones durante la última etapa como Estado autónomo y el primer periodo de la República 1847-1870. En Las Constituciones de Costa Rica, Volumen III. San José: Editorial UCR.

Obregón, C. (editora). (2007c). Costa Rica, las constituciones a finales del siglo XIX y la primera mitad del siglo XX 1870-1948. En Las Constituciones de Costa Rica, Volumen IV. San José: Editorial UCR.

Obregón, C. (editora). (2007d). Costa Rica, las constituciones durante su etapa como parte de las Provincias Unidas del Centro de América, de Estado de la República Federal de Centro América y de Estado autónomo 1824-1847. En Las Constituciones de Costa Rica, Volumen II. San José: Editorial UCR.

Tribunal Supremo de Elecciones (1999a). Sentencia n. ${ }^{\circ}$ 886-1999 de las 9:00 horas del 20 de abril.

Tribunal Supremo de Elecciones (1999b). Sentencia $n .{ }^{\circ}$ 1858-1999 de las 9:10 del 23 de setiembre.

Tribunal Supremo de Elecciones (2000). Sentencia n. ${ }^{\circ}$ 696-E-2000 de las 9:05 horas del 25 de abril.

Tribunal Supremo de Elecciones (2017). Sentencia n. ${ }^{\circ}$ 1626-M-2017 de las 11:35 horas del 1 de marzo. 